\title{
Depth Space and the Theory of Depth Space Control Power
}

\author{
Yiming Cai \\ Adjunct Professor of School of Management, Zhejiang Ocean University, China; Senior Economist \\ of Zhoushan Port Authority, Zhejiang, China \\ cym877@126.com
}

\begin{abstract}
Key Words: Human and Nature; Breadth; Depth; Sustainable; Land; Space Resources; Utilization; New Resources
\end{abstract}

\begin{abstract}
The ideas of energy-saving, environmental protection and low-carbon and all kinds of disciplines are of great relevance. Lack of resources and environmental deterioration are the serious but common problems that mankind are facing now. Being the first scholar to put forward the theory of breadth and depth of space to divide ocean development resources and other resources, the author once again originally found the depth space resources of the development and utilization of plant energy and other renewable resources on land and the characteristics of depth space resources, and also discussed his theoretical view on depth space resources control power deeply. In future, people who can scientifically and rationally develop and use energy and other resources will both own the key to harmonious development with nature concerning energy and other resources exploration of nations and human kind, and the key to peace and primary material base controlling the fate of the world and human.

The article focuses on the depth space development and the regarding new resources which will bring a broad and long-term interests and influence on resource and environment problems, the harmony of human society and sustainable development, as well as play a significant role in the area of economy and new geopolitics in the future.
\end{abstract}

According to present relevant materials, all fossil resources can only sustain human for 40 years while natural gas for 60 years.

Climate warming results in the rising of sea level, which, by 2100 , will make sea level rise 50 $\mathrm{cm}$. That absolutely will endanger all costal lowlands, such us Venice, Holland, etc.

About one third of the world's land faces threat of desertification [1].

Facing the threats of war and terrorists, people are not living in an environment but not peaceful and tranquil.

Shortage of energy and other resources, serious environmental degradation, and the complex social problems consequent on them have brought obstacles to the sustainable development of human society, which should not be ignored. Is it possible that there is a law of the usage of energy and other resources for mankind? All of those set man the deep thinking.

Depth space resources exist not only in ocean but also on land. Based on breadth and depth space concept of "ocean development" proposed by the author [2, 3], this paper focuses on biomass energy on land, solar energy, renewable energy and other resources in depth space and control power of depth space. 


\section{Breadth and Depth Spaces of Energy and Other Resources' Utilization}

Breadth and Depth Spaces of Resources. Dividing human's development and utilization of energy and other resources into breadth and depth spaces plays an important role in sustainable development of energy and resources, environment protection, reinterpreting and clarifying the relation between resources' development/utilization and space expansion.

If the development and utilization of resources can be divided by a cross coordinate, it can fit into two categories: breadth space resources (horizontal) and depth space resources (vertical). The former one is two-dimensional. It is the continuous extension on a horizontal "line"- "breadth" unlimited; while the energy and other resources of horizontal breadth spaces are limited in area and volume. They are non-renewable and with no depth, such as coal, petroleum and so on. Depth space is the continuous vertical extension on a "point" of a "line" in breadth space. To obtain energy and other resources on a point, such as solar energy and wind energy is inexhaustible because "depth" is unlimited. Besides, the recycle and utilization of scrap iron \& steel, petrochemical products, etc also belong to the development and utilization of depth space (refer with: Fig. 1, Fig. 2).

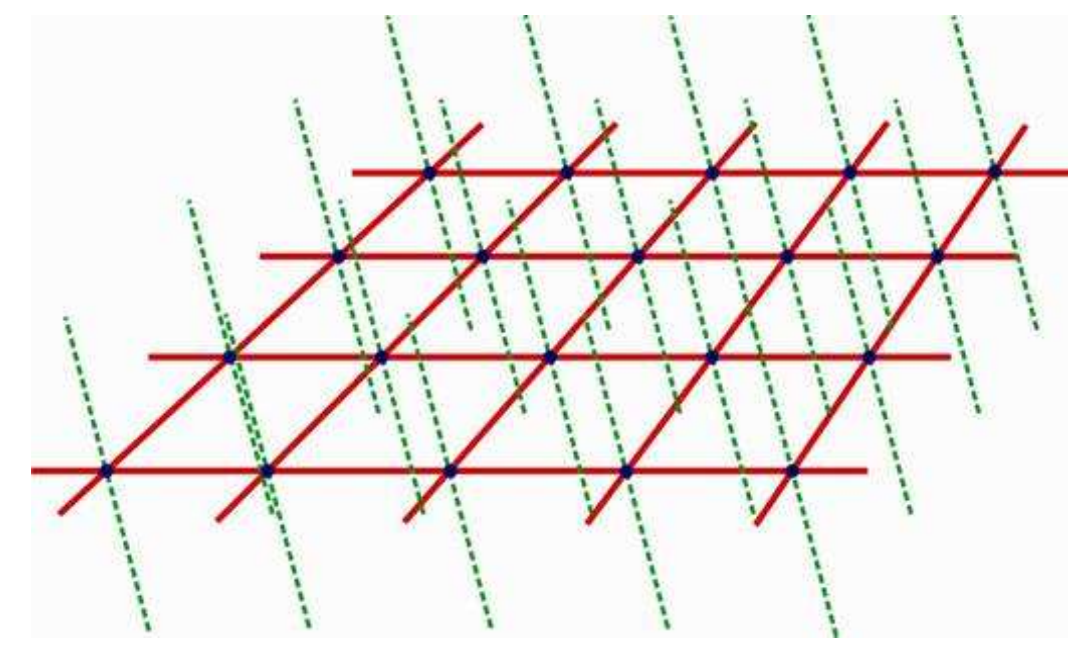

Breadth Space

Depth Space

. Extension on a point

Fig. 1 Three-dimensional Diagram of Breadth and Depth Space

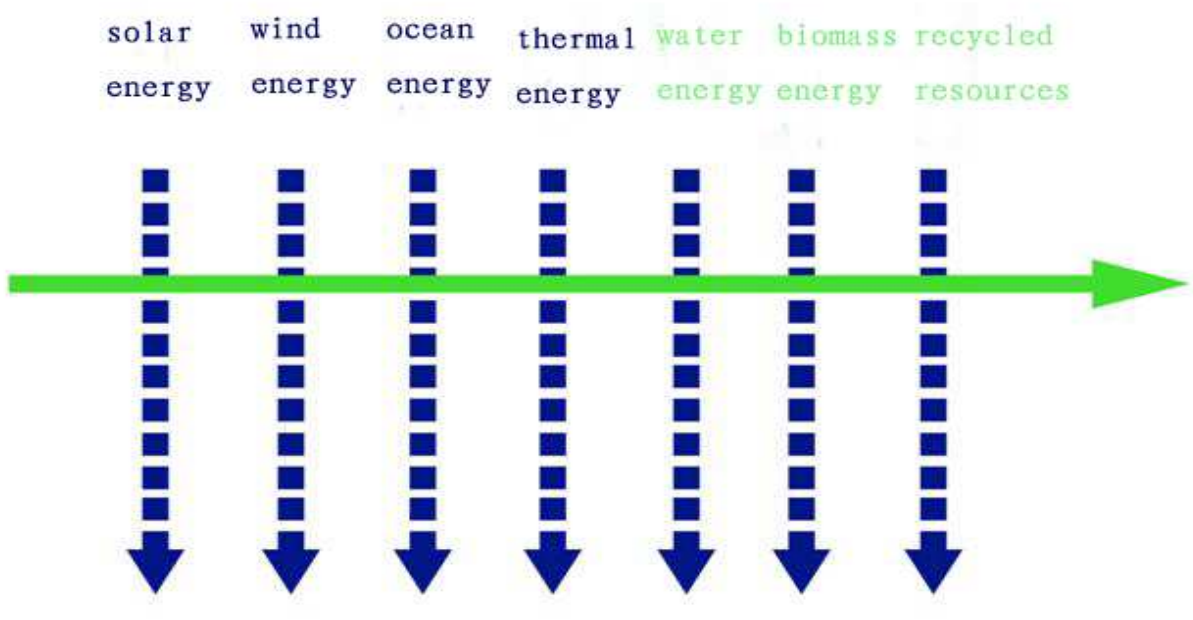

Fig. 2 Breadth and Depth Space relationship Diagram of Energy and Other Resources 
Conflicts between nation and nation, and those between human and nature are reflected mainly on that between resources interest and space. As the control of new energy resources' power and interest, depth space control will play an important role in politics, economics, diplomacy and other fields in future.

Depth Space Resources. Depth space resources are those renewable energies and other resources. Solar power, ocean power, water energy, wind energy, biomass energy, geothermal energy, recycled resources and other renewable and environment-protective energies can all be included into depth space resources.

The potential of solar energy is enormous since each day the earth receives in form of solar energy about 200,000 times the total world electrical-generating capacity [4].

In a narrow sense, solar power is limited to luminous energy, electric energy and photochemical direct conversion of solar radiation energy. However, in a broad sense, except for tidal energy and geothermal energy, all the renewable energies such as ocean energy, wind energy and biomass energy come from the huge power of solar radiation. As the sun will exist for 5 billion years more, thus solar power can be considered as inexhaustible for human (refer with: Fig. 3) .

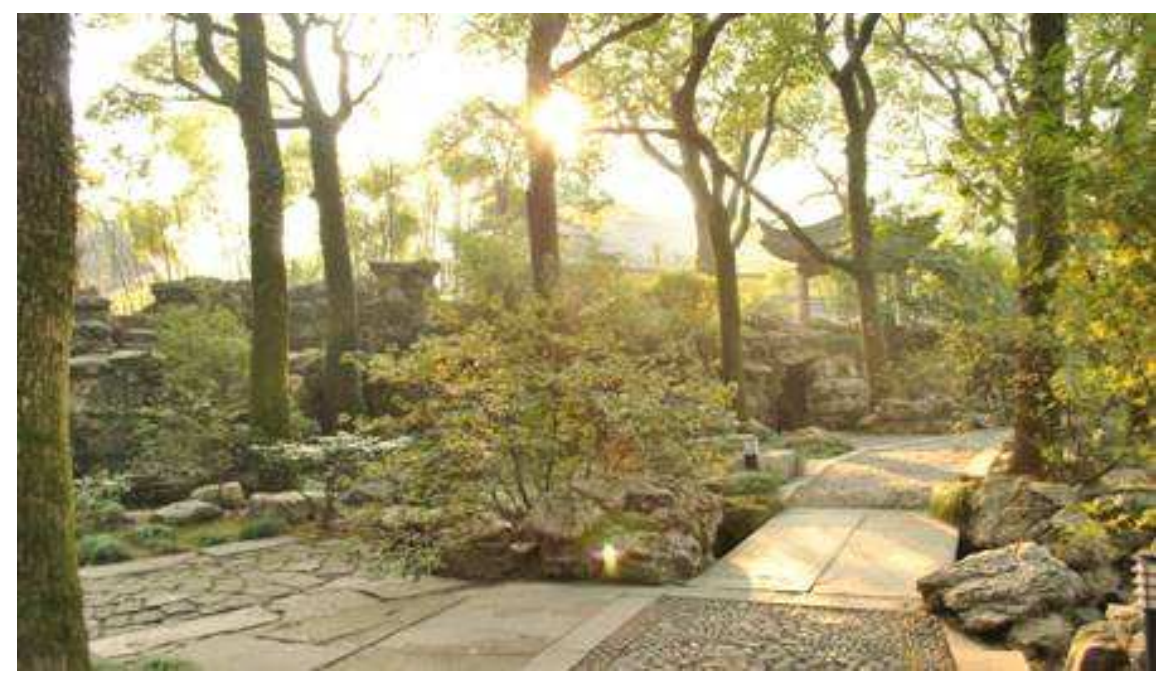

Fig. 3 As the sun will exist for 5 billion years more, thus solar power can be considered as inexhaustible for human.

Photo credit: Author.

From a number of popular science textbooks, we can learn about following things. Ocean flows with enormous energy. It is estimated that worldwide theoretical tidal energy reserve is of about $3 \times 10^{8} \mathrm{kw}$, wave energy of about $700 \times 10^{8} \mathrm{kw}$, current energy of about $50 \times 10^{8} \mathrm{kw}$, thermal energy of about $20 \times 10^{8} \mathrm{kw}$ and Salinity Energy of about $26 \times 10^{8} \mathrm{kw}$. These energies are hundreds times as much as the world's energy consumption. Total wind energy of the world is $2 \times 10^{13} \mathrm{w}$, nearly accounting for 3 times as much as the world's energy consumption per year. Geothermal energy is the power gained by using the Earth's interior heat. Only of a layer of 10 kilometer' underground, heat storage is equivalent to that released by $9.95 \times 10^{15}$ tons of standard coal.

According to the statistical data of International Water Power and Dam Construction Handbook in 1996, the world's theoretical hydropower reserve is 41.3095 trillion kw hours / year, of which $11.7549 \mathrm{kw}$ hours/year is exploitable by technology [5].

Air energy refers to the energy released from air due to its physical changes without chemical changes occurring. Air changes in temperature, flow velocity, atmospheric pressure and humidity. Any kind of physical changes of air is accompanied by energy changes.

Biomass energy refers to those which derive from straw, wood, animal dung and other biomass. Although only very small part of solar energy is fixed in organic matters on land, it is seven times as the world's consumption per year. 
Energy plant is also a kind of biomass energy resources.

Recycled Resources means recycling and utilization of scrap steel, waste glass, waster paper and other resources, as well as the energy regeneration treatment of solid wastes in cities. Through the repeated and renewable utilization between "point" and "point", resources are constantly "copied" (developed) and utilized cleanly. Therefore, recycling can be included in the development and utilization of renewable energy and other resources.

Other Depth Space Resources. To human, the depth space of resource used in earliest times are not unfamiliar, such as soybean, wheat, cotton and rubber.

Depth space resources can be also divided in to two categories, which are energy-related and resource-related. Some of these resources already have been the most important and essential resources in our life.

Depth space resources include solar power, ocean energy, biomass energy, geothermal energy, and other renewable environment-protective energy and resources. Due to the limitations of space, following article mainly takes depth space resources-biomass resources for example, discussing its utilization.

\section{Biomass Resources}

Listed behind coal, petroleum and natural gas, biomass ranks in the 4th place in total global energy quantity. Biomass currently is, as it were, the only substitute resource to renewable and environment-protective liquid fuel. According to relevant materials, by the middle of 21 st century, various biomass substitute of fuel produced by nee technology will be cheaper than fossil fuels and will provide $60 \%$ electricity power and $40 \%$ fuels of whole world [6].

Energy plant usually refers to those that contain higher reductive hydrocarbon capacity and can produce products with components close to petroleum's and replace petroleum itself, as well as those that are rich in oil.

Environment-friendly Feature of Biomass Energy Utilization. Biomass energy is green and clean energy as biomass fuels contain with low contents of sulfur and nitrogen and produce very little sulfur and nitrogen oxides during burning. Besides, biomass can be biodegraded under natural conditions. As the carbon dioxide released during burning almost equals that needed during growth, the two counteract each other. Therefore, net carbon dioxide amount is close to zero and it can effectively reduce green house effect.

Price of Biomass Energy. The conversion and utilization technology of biomass energy is developing at an extraordinary rapid speed. According to experts, cost to plant energy grass in Beijing is RMB 70-80 per acre per year, which will produce 3 tons of energy grass; basis on a laboratory refining ratio of 4.5:1, energy grass of each acre can produce 0.67 ton of liquid fuel. The latest America's catalytic reaction technology can directly convert biomass into gasoline and diesel oil with a cost less than RMB 2 per liter and quality equivalent to or better than those produced by fossil [7].

\section{Depth Space Development in Desert}

The main purpose to put up with breadth and depth spaces theory is to explore the scientificalness in mankind's utilization of energy and other resources, and to clarify fuzzy concepts in utilization of resources space based on the theories of sustainable development, ecological ethics and some others. 
With the development of science, human have successfully opened two new living space-deserts on the Earth and the moon. According to the relevant materials of UNESCO, human's productive and social activities obviously aggravate land desertification. The Earth is degenerating. It is estimated that about 24 billion acres of farmland disappeared each year. In the past 20 years, loss of the Earth's surface roughly equals to the total farmlands in the United States. Now, land affected by desertification reached one fourth of the total land on Earth [1]. The total area of the Moon is close to that of the desert on Earth. Shall we develop moon space or desert space? According to present human's technological level, obviously the latter one is more economic and practical.

As desert is much sunny, hot and dry, it receives very strong sun radiation. Desert is abundant in renewable energy and other resources, thus making itself the main base of luminous energy in future. A desert must have strong winds which can be turned into luminous energy, heat energy and mechanical energy. Strong ultraviolet radiation, photosynthesis and temperature difference between day and night in desert are all conductive to sugar accumulation in plants, planting sweet fruit and cultivating cotton and wheat. The sands can be used in construction and to improve alkaline earth and clay. They also can be used to produce glass and refine of silicon. The characteristics of desert are beneficial to generating a wide variety of secondary metabolites, including terpenoids, alkaloids, phenolic compounds (including flavonoids) and so on. A large proportion of desert plants are suffurticosa plants. The main families and genera include composite, knotweed, pea famility, agavaceae, burseraceae, etc. Israelites use sprinkler and drip irrigation to produce fruits, flowers and herbs. The annual output value of each agricultural worker reaches at USD25, 000, more than the average output value of the U.S. workers (USD 22,000) [8].

An important feature of depth space energy utilization is that energy and resources can be continuously extended and copied at one point. For example, plants energy is planted and harvested at a same point to gain energy and other resources. The process is repeated again and again. Similarly, solar power, wind energy and geothermal energy are also to gain energy at a point constantly (refer with: Fig. 4).

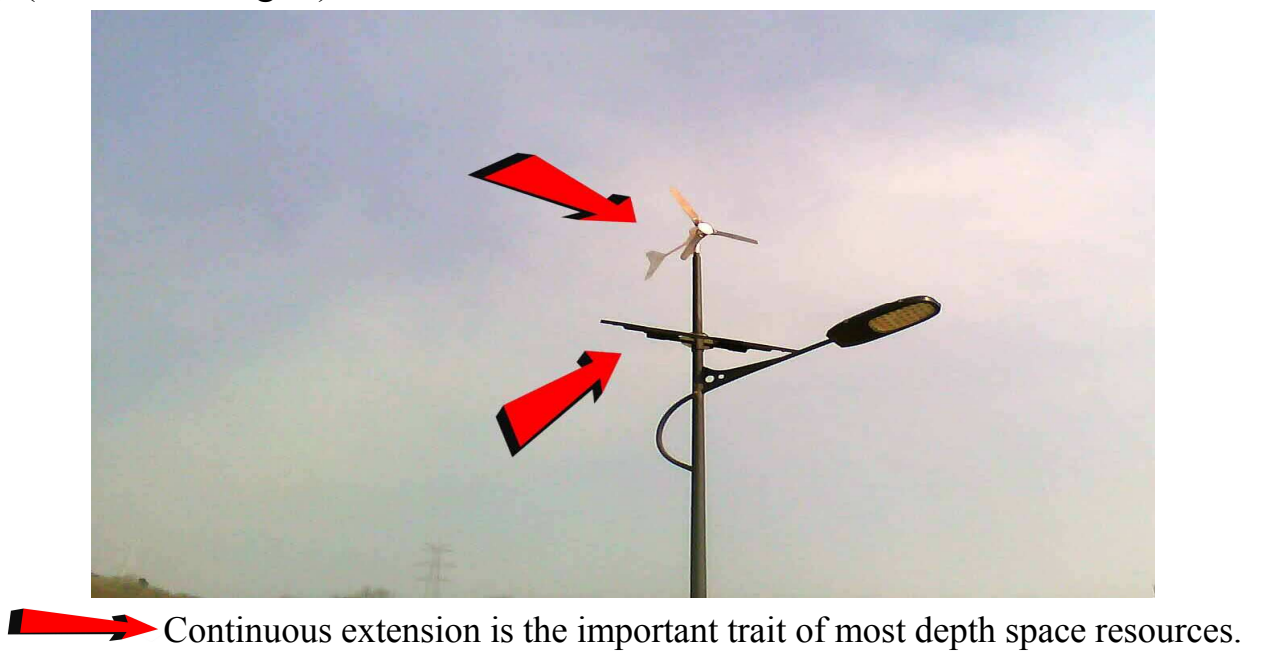

Fig. 4 Plant energy, wind energy, geothermal energy all gain energy and other resources on a same point. The picture shows the combined lights of wind energy and solar energy installed in the street. Photo credit: Author.

Sand plants attract great attention of economic circle like bright stars during the development upsurge of sand plants in recent years.

Jojoba, pronounced (Simmondsia chinensis) is a shrub native to the Sonoran and Mojave deserts of Arizona, California, and Mexico. It is also known as goat nut, deer nut, pignut, wild hazel, quinine nut, coffeeberry, and gray box bush. Jojoba is grown commercially for its oil, a liquid wax 
ester, expressed from the seed. Its seeds contain a special substance of which $50 \%$ is liquid wax, being a perfect substitute for spermaceti. Man uses it as the lube oil for varieties of high-speed engines. In America, this plant wax is used as lubricating material in many high-speed racing cars and vehicles. The plant has also been used to combat and prevent desertification in the Thar Desert in India [9].

Euphorbia tirucalli (also known as Firestick Plants, Naked Lady, or Milk Bush) is a shrub that grows in semi-arid tropical climates, largely in Africa, being prominently present in northeastern, central and southern Africa. Milk bush is a hydrocarbon plant that produces poisonous latex which can, with little effort, be converted to the equivalent of gasoline. Test shows that people can plant euphorbia tirucalti in dry deserts successfully. This led chemist Melvin Calvin to propose the exploitation of milk bush for producing oil [10].

Through a lager number of cultivation and introduction tests by plant scientists, bright sand stars also include Euphorbia antisyphilitica, Eucalypius, Bursera, Parthenium argentatum and so on.

Compared with the first generation of biomass fuels which takes corns and beans as raw materials, the second generation of biomass fuels, taking algae, straw and other plant fiber as raw materials, enjoy tremendous advantages of not fighting with men for grains, rapid growth and high yields. It is learned that a botryococcus braunii growing in fresh water can discharge liquid fuel oil directly, just like a oil-producing machine.

The future value of the desert is also reflected in the production of algae. As for utilization rate of solar energy, desert algae (Chlorella, Cyanobacteria, Spirulina) is much higher than advanced plants. Solar power utilization rate of general advanced plant is just $1 \%-2 \%$, while Chlorella reaches $10 \%$ with protein content of $50 \%$. Spirulina contains $70 \%$ of protein and almost all kinds of amino acids, vitamins needed by body and digestibility of those substances is up to $70 \%$. The algae living in desert with thicker sheath not only play an important ecological role in sand fixation, nitrogen fixation and plant community succession, but also is one significant source of food in future. Chlorella cell can divide four times in 24 hours, while the Spirulina found in salt lake of South Africa's Sahara Desert can split 10 times in 24 hours. Now, the United States, Kuwait, Egypt, Japan and other countries and regions have built a certain amount of algae bases and make health products form these algae [8].

\section{Depth Space Control Power}

Breadth and Depth Space include land, ocean and "new ocean" (refer with: Note 1/Fig. 5).

Note 1 When the author academically put up with that human can divide development and utility of energy and other resource into breadth and depth spaces for the first time in 2008, he thought ocean development is the outward expansion and extension to the utility of human activity space and resources. Understanding form this concept, space can be explained as the "new ocean" of human activities. 


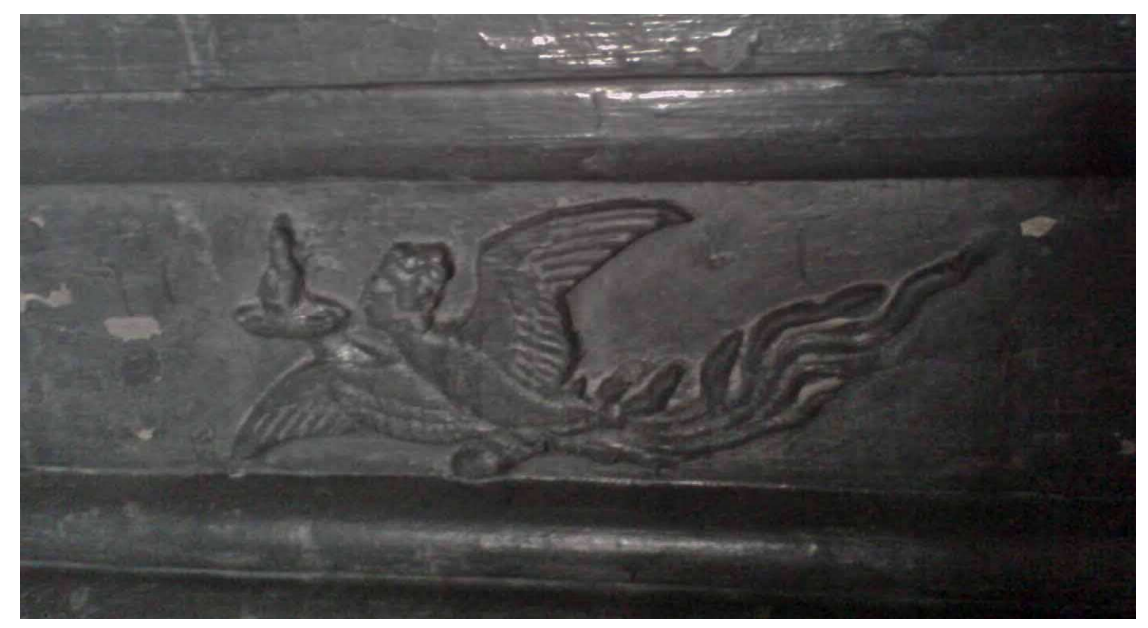

Fig. 5 Human have been expecting for a long time to fly into sky and space. The picture shows ancient man flying into the sky on the sculpture of the ancient architecture. Photo credit: Author.

Depth space control or depth space control power is a new term. It aims to clearly express and understand new "political" and "economic" geography phenomenon in objective world [11]. The depth space in natural science is inexhaustible and unlimited "depth" renewable and environment-protective energy and other resources. While in social science, it can develop into the depth control power which is tightly associated with politics, economics, diplomacy and military (refer with: Note 2).

Note 2 The theory of depth control power has been put forward for 2 years. In Chinese characters, power and right are represented by one character so that some western scholars feel confused about the translating right into power. The reason why the author translates right into power are these two points: first, sever resources shortage and serious environment pollution are badly in need of protection of a strong force; second, the translation of depth space control power as ocean, land and air power will make the point more easily understood. From the geopolitics depth space control power is also a new kind of control power. Depth control power owns the meaning of both power and right.

Fossil energy (coal, petroleum) is the fundamental energy resources to cause fierce competitions and fights among nations concerning traditional interest in control power of sea power, land power and air power in "breadth space". Divided by political geography, sea power, land power and air power belong to geopolitics. While depth space control power is another new "geopolitics" since human entered 21st century-renewable times, it is the space control power of new generation resources interest.

After World War II, international community took warning from the painful lessons brought by war. Diverted from mainly controlling sea, land and air powers, men become more inclined to gain "control of business circle"; relations between nations will develop towards a friendly direction while under steady transactions. Most of competitions are those in market economy. The main aim of recent and modern nations' sea, land and air powers finally will connected with acquirement of economic rights and interests.

Through practicing depth space control power, we can, for example, solve the sensitive problems in petroleum war. In the final analysis, market competitions are those of products, resources and prices. By using price leverage, development and utilization efficiency of renewable resources can be enhanced. World's energy markets are interlinked. The markets of petroleum, coal, 
wind power, solar power and other energy resources are affected by resources' reserves. They affect and tie up with each other. That actively supporting depth space development of solar power, biomass energy and other resources, and forming certain economy scale and using depth space control power, will finally affect the products and market of energy and other resources in international petroleum sensitive areas, so as to solve sensitive problems of international petroleum and create good conditions for harmonious development basis on energy market, resources and environment.

In future, people who can scientifically and rationally develop and use energy and other resources where mankind need who own the key to harmonious development with nature concerning deplore energy and other resources of nations and human, and own the key to peace and primary material base controlling the fate of world and human(refer with: Fig. 6).

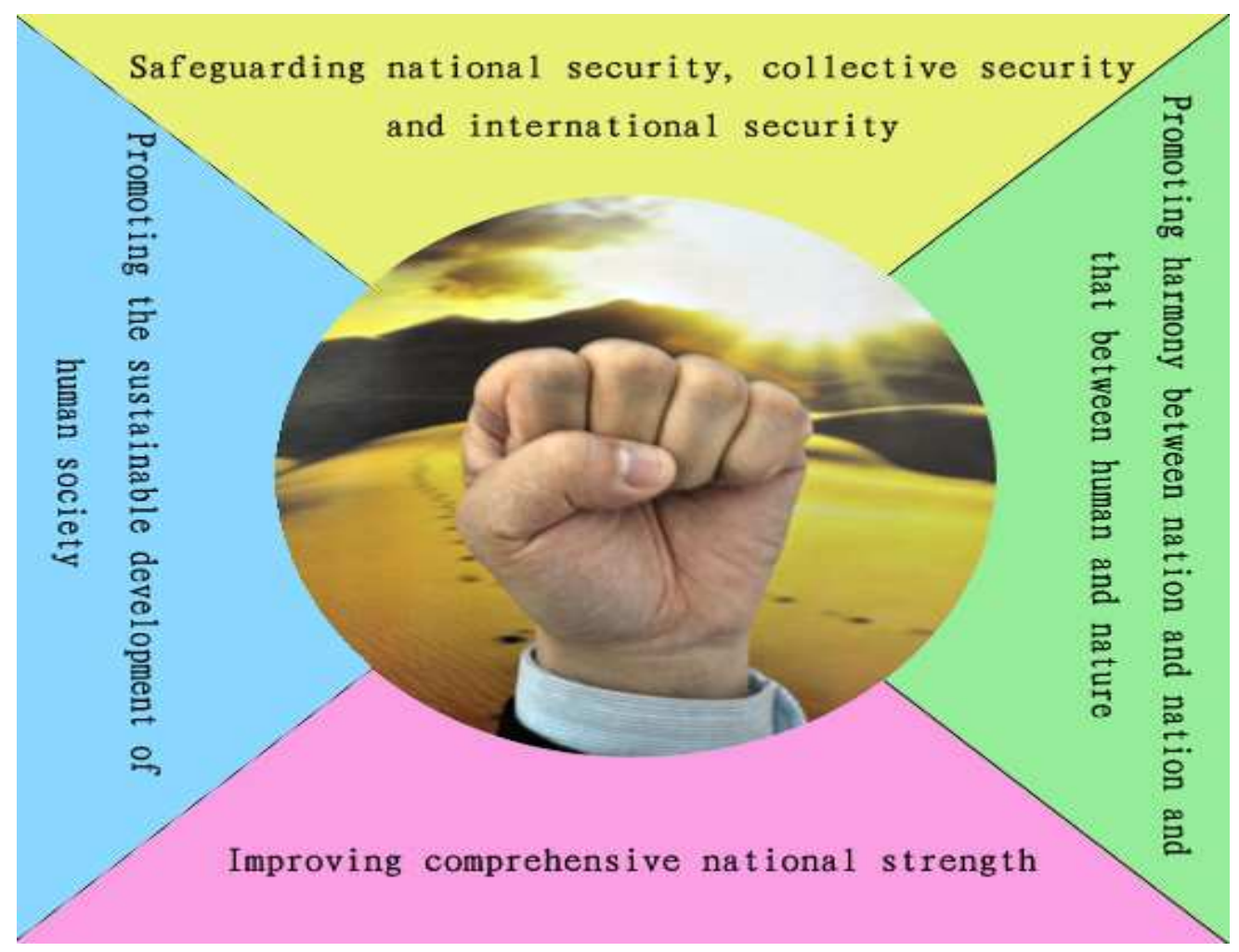

Fig. 6 The Role of Depth Space Control Power. Photo credit: Author.

Customarily, sea, land and air powers are mainly reflected as competitions of breadth space control power. Control of energy and other resources belongs to "breadth" horizontal control and it is control of "plane surface". Depth space control power is the "depth" vertical right and interest control of renewable resources. It is not a result of productive forces development and differs from traditional interest control power. It is the new and important control power of human interests with harmonious development and significant progress meaning.

\section{Characteristics of Breadth and Depth Control Power}

Though breadth and depth space theory seems simple, it deeply reveals a coordinate system which should be recognized scientifically by human society in utility of important energy and resources but was neglected.

Main characteristics of breadth and depth space control power are:

Utility of energy and other resources shows constant "extension" and "copy" on a "point".

Depth space resources exist both on land and in ocean. Concept of breadth and depth space control power also include space---"new ocean". 
Breadth and depth space are both endless. Breadth space constantly extends to land, ocean and New Ocean in micro space, while depth space resources such as solar energy, plant energy and other renewable resources are endless.

Some depth space resources also include the recycle and utility between "point" and "point", such as recycle and utility of scrapped steel, newspapers, glass and other renewable resources.

Breadth and depth space control power is the only one that can use the coordinate system to explain the cross relationship between resource control power and sea, land and air power, as well as the harmonious sustainable development (refer with: Fig. 7).

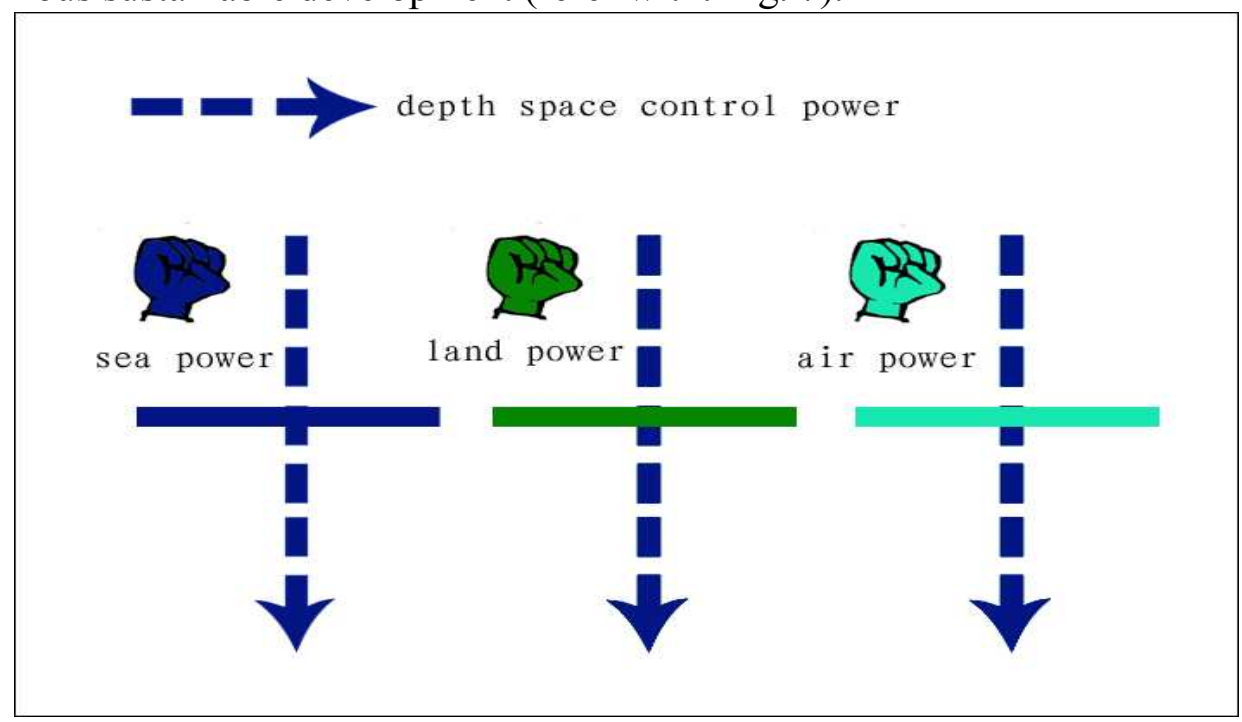

Fig. 7 Relationship Diagram of sea power, land power, air power and depth space control power.

"Ocean" depth space control power, in fact, is that stepping across sea power, land power and air power, and that can be continuously extended and "copied" on any point in ocean, on land and in the air.

Utility of some energy and other resources shows multi-level constant extension and "copy" on a "point" in the flat reasonable space. Take a metaphor for understand. In a seven-story building, we can collect and utilize solar power both vertically and horizontally at every window, as well as wind power and other renewable resources. This is significant to the utility rate estimate of solar and other renewable resources. (Although depth space resources are very rich, it needs to be reasonably and scientifically used in space layout, not the more, the better.)

Most depth space resources possess "four-dimensional" character, first strait line; second plane surface, third solid and fourth new times and new time.

Though breadth and depth space theory looks simple, recognizing the role of coordinate system in geopolitics and resources utility holds a very important and positive practical significance to the healthy development of human society in future.

\section{Developing and Utilizing Depth Space at an Environment-protective and Mercy Standards}

Any method of energy utilization will impact on environment, but the point is how to minimize the impacts.

Take impact on environment from wind power generation for example. There is great controversy about the injuries and deaths to birds and bats caused by wind power generation. Some wind electric fields have large observation data bases and some have small ones. This is probably related to locations. Pinaska wind energy station, Texas, USA, raised a new tactics. They use radar system to protect birds which was designed for NASA and air forces. The radar system can discover approaching birds in a scope of 4 miles. If the system judges some bird may hit the turbine, the 
turbine will be automatically shut down until the bird leaves safely and then it will be restarted [12]. Wild animal experts pointed out that choosing suitable installation locations for turbines is the most important factor to protect birds.

One of the main reasons to rapid expansion and spreading of global land desertification is impact of human's activities. Cultivating energy plants on desertificated lands can not only prevent rapid expansion of desertification but also prevent and improve sand invasion. Besides, it won't compete with people for farmland and supply men with biomass fuels of second generation, achieving many things at one stroke. However, the rapid growth of plants may lead to loss of land nutrition. Concerning this, scientists have made enormous studies on plant introduction, watering, fertilization and other cultivation technologies and reached some encouraging results. Of course, more studies and improvements are stilled needed for some technology problems. In addition, some problems need to be further studied such as how large oasis should be kept on Earth for the most suitable to mankind's life, what' s the role of desert area in climate formation, and shall we keep certain desert? Rapid industry development caused serious environment problems so might the new technology practice of renewable energy and other resources.

From the ancient society to today's information times, especially after the industry revolution of recent times, as the lord of creation (refer with: Note 3), human experienced great changes in transformation and utilization ability of nature. At the same time, destruction power almost increased in direct preparation.

Note 3 Ancient Chinese proverb holding that compared to animals, human is the wisest and adroit.

During the development and utilization process of depth space, high responsibility and mercy exactly show the progressiveness of the lord of creation As the control and development of advanced, new, sustainable and environment-protective energy, depth space should reflect the high responsibility and mercy of lord of creations-human for man's own living space and all creations during exploring Nature and working for the welfare of people. Men also should set the most advanced, protective and humane standard for the control and utilization of depth space resources.

\section{Acknowledgements}

As a compound and creative front-line theory, deep space and the theory of deep space control was first put forward by me during a long thinking period. So I would like to express my sincere gratitude to all those who gave me the possibility to complete this paper.

First of all, a special acknowledgement should be shown to the experts and scholars, who recommend and evaluate my paper.

Secondly, I am grateful to those who gave proper suggestions, valuable information or sharp criticism to my paper, which have been of great help to make my paper's structure and theories more reasonable, and help I benefited greatly.

I am particularly indebted to Prof. Lu Bingquan, Energy geologist of Tongji University, who proof-read the energy statistics for my paper, and also the kind help and support all through my writing from Prof. Xu Jianhua, Miss Cao Yunhong and Miss Chen Yanhong.

Finally, I want to thank all of the experts, scholars and colleagues for their stimulating support. 


\section{References}

[1] UNESCO.2005. Learning to Combat Desertification "In Chinese". Beijing: Chemical Industry Press.

[2] Yiming Cai. 2008. Learning from the Theory on Maritime Hegemonies and Building Contemporary Harmonious Oceanography “In Chinese”. World Regional Studies 17(4): 41-48.

[3] Yiming Cai. 2010. On the Width of Space and the Depth of Space for "Ocean" Development. BIT's1st Annual World MarineTech Summit- 2010, Dalian, China. http://www.bitconferences.com/mts2010/cn/default.asp (last accessed 27 February 2011).

[4] The new encyclopedia Britannica in 15th edition. 2008. Chicago. Encyclopedia Britannica. Inc. (10):941.

[5] China Digital Science and Technology Museum. 2011. Earth Resources Expo Museum (Energy Resources) "In Chinese". http://amuseum.cdstm.cn/AMuseum/diqiuziyuan/er2_0_1.html(last accessed 21 March 2011).

[6] Xinxiang Fang, Yun Bai, Aihua Chen, and Haixia Zhu. 2008. Green Energy-biomass energy "In Chinese". Modern Chemical Industry. (28) Supplement (2): 21.

[7] Aihua Deng, Beijing Explores New Forms of Biomass Energy. "Plant" Petroleum in Fields in Future “In Chinese”. (http://tech.sina.com.cn/d/ 2009-08-26/08313384383.shtml (last accessed 21 March 2011).

[8] Shiwei Ma,etc.. 1998. Desert Studies "In Chinese". Huhehaote Municipality, China: Inner Mongolia People's Publishing House: 5,7.

[9] Wikipedia, the free encyclopedia. (http://en.wikipedia.org/wiki/Jojoba (last accessed 27 February 2011)

[10] Wikipedia, the free encyclopedia. (http://en.wikipedia.org/wiki/Euphorbia_tirucalli (last accessed 27 February 2011)

[11] Yiming Cai. 2009. Control Rights of the Ocean's Depth Space -The Exploration of Energy Resources in the Ocean's Deep Space "In Chinese”. World Regional Studies 18(4):50-55.

[12] Guardian. 2009. The Texas applies radar technology in wind power to protect migratory Birds "In Chinese". (http://www.fenglifadian.com/news/13579CK8G.html(last accessed 27 February 2011). 